\title{
Preferential Increases in Nucleus Accumbens Dopamine after Systemic Cocaine Administration Are Caused by Unique Characteristics of Dopamine Neurotransmission
}

\author{
Qun Wu, ${ }^{1}$ Maarten E. A. Reith, ${ }^{2}$ Michael J. Kuhar, ${ }^{3}$ F. Ivy Carroll, ${ }^{4}$ and Paul A. Garris ${ }^{1,2}$ \\ ${ }^{1}$ Cellular and Integrative Physiology Section, Department of Biological Sciences, Illinois State University, Normal, Illinois \\ 61790-4120, ${ }^{2}$ Department of Biomedical and Therapeutic Sciences, University of Illinois College of Medicine at Peoria, \\ Peoria, Illinois 61656-1649, ${ }^{3}$ Neuroscience Division, Yerkes Regional Primate Research Center, Emory University, Atlanta, \\ Georgia 30322, and ${ }^{4}$ Chemistry and Life Sciences, Research Triangle Institute, Research Triangle Park, North Carolina \\ 27709-9981
}

In vivo voltammetry was used to investigate the preferential increase of extracellular dopamine in the nucleus accumbens relative to the caudate-putamen after systemic cocaine administration. In the first part of this study, cocaine (40 mg/kg, i.p.) was compared with two other blockers of dopamine uptake, nomifensine (10 $\mathrm{mg} / \mathrm{kg}$, i.p.) and $3 \beta-(p$-chlorophenyl)tropan$2 \beta$-carboxylic acid $p$-isothiocyanatophenylmethyl ester hydrochloride (RTI-76; 100 nmol, i.c.v.), to assess whether the inhibitory mechanism of cocaine differed in the two regions. All three drugs robustly increased electrically evoked levels of dopamine, and cocaine elevated dopamine signals to a greater extent in the nucleus accumbens. However, kinetic analysis of the evoked dopamine signals indicated that cocaine and nomifensine increased the $K_{\mathrm{m}}$ for dopamine uptake whereas the dominant effect of RTI-76 was a decrease in $V_{\text {max }}$. Under the present in vivo conditions, therefore, cocaine is a competitive inhibitor of dopamine uptake in both the nucleus accumbens and caudate-putamen. Whether the preferential effect of cocaine was mediated by regional differences in the presynaptic control of extracellular DA that are described by rates for DA uptake and release was examined next by a correlation analysis. The lower rates for dopamine release and uptake measured in the nucleus accumbens were found to underlie the preferential increase in extracellular dopamine after cocaine. This relationship explains the paradox that cocaine more effectively increases accumbal dopamine despite identical effects on the dopamine transporter in the two regions. The mechanism proposed for the preferential actions of cocaine may also mediate the differential effects of psychostimulant in extrastriatal regions and other uptake inhibitors in the striatum.

Key words: cocaine; dopamine; caudate-putamen; nucleus accumbens; voltammetry; uptake
Mesoaccumbal dopamine (DA) neurons play a key role in mediating the behavioral effects of cocaine (Wise, 1996; Kalivas and Nakamura, 1999; McBride et al., 1999). At the cellular level in the nucleus accumbens (NAc) the psychostimulant acts by inhibiting the DA transporter that subsequently increases extracellular levels of DA activating postsynaptic receptors (Koob and Bloom, 1988; Kuhar et al., 1991). Interestingly, in vivo studies demonstrate that cocaine increases extracellular DA to a greater extent in this limbic area compared with the sensorimotor caudateputamen (CP) (Carboni et al., 1989; Cass et al., 1992, 1993; Kuczenski and Segal, 1992), which receives the densest dopaminergic innervation in the brain (Bjorklund and Lindvall, 1984). The preferential effects of cocaine are additionally surprising because the drug exhibits a similar potency for binding to the DA transporter and for inhibiting DA uptake in the two regions (Boja and Kuhar, 1989; Izenwasser et al., 1990; Cass et al., 1992; Jones et al., 1995a). A different inhibitory mechanism for cocaine may explain the paradox. Despite extensive study, however, this mech-

\footnotetext{
Received Jan. 22, 2001; revised May 15, 2001; accepted May 16, 2001.

This work was supported by National Institutes of Health Grants NS 35298 (P.A.G.) and DA 08379 (M.E.A.R.). We kindly thank Steve Juliano for assistance with the statistical analysis.

Correspondence should be addressed to Dr. Paul A. Garris, 244 Science Laboratory Building, Department of Biological Sciences, Illinois State University, Normal, IL 61790-4120. E-mail: pagarri@ilstu.edu.

Copyright (ㄷ) 2001 Society for Neuroscience $0270-6474 / 01 / 216338-10 \$ 15.00 / 0$
}

anism remains highly controversial because cocaine has been described as either a competitive (Cao et al., 1989; Krueger, 1990; Jones et al., 1995a), noncompetitive (Missale et al., 1985; Povlock and Schenk, 1997), or uncompetitive (McElvain and Schenk, 1992; Wheeler et al., 1994) inhibitor of DA uptake without consensus on regional differences between the NAc and CP (McElvain and Schenk, 1992; Jones et al., 1995a; Povlock and Schenk, 1997).

Intrastriatal differences in DA neurotransmission may also play a role. Cass et al. (1992) postulate that a lower number of DA uptake sites in the NAc compared with the CP is responsible for the preferential increases in extracellular DA elicited by cocaine in the rat. This hypothesis is supported by the differential effects of cocaine in the medial versus the lateral striatum (Cline et al., 1995) and recent work in the nonhuman primate (Bradberry et al., 2000; Cragg et al., 2000). However, DA uptake rates in the amygdala and cortex are slower than those in the striatum (Garris and Wightman, 1994; Jones et al., 1995b); yet cocaine-induced increases in extracellular DA are less (Moghaddam and Bunney, 1989; Garris and Wightman, 1995a; Hurd et al., 1997), suggesting that other factors are involved.

This study used in vivo voltammetry (Garris and Wightman, 1995b) to investigate the differential effects of cocaine on extracellular DA in the NAc and CP. The inhibitory mechanism of cocaine was examined first. In these experiments cocaine was compared with two other blockers of DA uptake, nomifensine, a 
competitive inhibitor, and $3 \beta$ - $(p$-chlorophenyl)tropan- $2 \beta$ carboxylic acid $p$-isothiocyanatophenylmethyl ester hydrochloride (RTI-76), a noncompetitive inhibitor. Next, the increase in extracellular DA elicited by the inhibitors was correlated with rates for DA release and uptake measured in the two regions. The present results suggest that the greater effects of cocaine in the NAc are caused by lower rates for DA release and uptake compared with those in the CP. This mechanism may also mediate the differential effects of other uptake inhibitors in the striatum and of cocaine in extrastriatal regions.

\section{MATERIALS AND METHODS}

Animals. Adult male Sprague Dawley rats (250-400 gm) were purchased from Harlan Sprague Dawley (Indianapolis, IN) and housed in the vivarium at Illinois State University. Rats were housed two per cage, and food and water were provided ad libitum. Animal care, in accordance with the Guide for the Care and Use of Laboratory Animals (NIH publication $865-23$, Bethesda, MD), was provided by a certified lab animal technician and supervised by a veterinarian. All animal care procedures were approved by the Institutional Animal Care and Use Committee of Illinois State University.

Surgery. Rats were anesthetized with urethane $(1.5 \mathrm{gm} / \mathrm{kg}$, i.p.) and immobilized in a stereotaxic apparatus (David Kopf Instruments, Tujunga, CA) as described previously (Bergstrom and Garris, 1999). Additional anesthesia was administered if required at one-third of the initial dose. Temperature was maintained at $37^{\circ} \mathrm{C}$ using Deltaphase Isothermal Pads (Braintree Scientific, Braintree, MA). Holes were drilled through the skull for the placement of reference, working, and stimulating electrodes. Flat skull coordinates are given in millimeters and were obtained from the atlas of Paxinos and Watson (1986). Anteroposterior (AP) and mediolateral (ML) positions were referenced from bregma, and dorsoventral (DV) positions were referenced from dura.

Two working electrodes were implanted in the right brain of each rat for simultaneous recording in the CP and NAc. Stereotaxic coordinates were 0.7-1.2 AP, 2.5-3.0 ML, and -4.5 to $-5.0 \mathrm{DV}$ for the $\mathrm{CP}$ and 0.9-1.4 AP, $1.4-1.7 \mathrm{ML}$, and -6.5 to $-7.0 \mathrm{DV}$ for the NAc. The recording sites in the NAc are considered the core region (Garris et al., 1994). The working electrode in the $\mathrm{CP}$ was lowered at a $12^{\circ}$ angle to reach the final coordinates without obstructing recordings in the NAc. The stimulating electrode was placed in the ipsilateral medial forebrain bundle ( -4.0 to $-4.6 \mathrm{AP}, 1.0-1.4 \mathrm{ML}$, and -7.5 to $-9.0 \mathrm{DV})$. The location of DA fibers was determined by lowering the stimulating electrode until a robust signal was recorded in both the NAc and $\mathrm{CP}$ during a $60 \mathrm{~Hz}, 2 \mathrm{sec}, 300 \mu \mathrm{A}$ stimulation. The reference electrode was implanted contralaterally in superficial cortex (approximately $+2 \mathrm{AP}$ and $-3 \mathrm{ML}$ ). After optimization of stimulating and working electrodes, the location of electrodes was not changed for the entire period of data collection.

RTI-76 was microinjected intracerebroventricularly either 1 or $2 \mathrm{~d}$ before voltammetric experiments by following the procedure of Garris et al. (1997) with some modification. Rats were anesthetized with Equithesin $(3 \mathrm{ml} / \mathrm{kg}$, i.p.) and placed in a stereotaxic apparatus as described above. A single hole was drilled through the skull for placement of the injection needle (30 gauge hypodermic tubing sharpened at the tip; Small Parts, Miami Lakes, FL). The needle was lowered to -0.25 AP, 1.4 ML, and -4.0 to $-5.0 \mathrm{DV}$, and $100 \mathrm{nmol}$ of RTI-76, dissolved in $10 \mu \mathrm{l}$ of sterile saline, was infused at a flow rate of $0.5 \mu \mathrm{l} / \mathrm{min}$ using a microsyringe pump (KD Scientific model 100; Fisher Scientific, Fair Lawn, NJ). The injection site was ipsilateral to sites for voltammetric recordings. After injection, the needle remained at the injection site for an additional $5 \mathrm{~min}$. The needle was then retracted, the hole in the skull was sealed with bone wax, and the scalp was sutured.

Electrical stimulation. The stimulating electrode was a twisted, bipolar electrode with 0.2 -mm-diameter tips separated by $1 \mathrm{~mm}$ (Plastics One, Roanoke, VA). The entire length of the stimulating electrode was insulated except for the exposed tips. Electrical stimulation was computergenerated, synchronized with the voltammetry, and optically isolated (NL 800 Neurolog; Medical Systems Corporation, Great Neck, NY). Constant-current, biphasic square-wave pulses were applied $(300-400$ $\mu \mathrm{A}$ and $2 \mathrm{msec}$ each phase). The duration of all stimulus trains was $2 \mathrm{sec}$. Frequencies between 10 and $60 \mathrm{~Hz}$ were chosen and randomly applied.

Electrochemistry. Cylinder carbon fiber $(r=2.5 \mu \mathrm{m})$ microelectrodes were prepared as described previously (Cahill et al., 1996). The carbon fiber extended beyond the glass insulation for $\sim 50$ to $100 \mu \mathrm{m}$. Electrochemistry was computer-controlled (Wiedemann et al., 1991) and used an EI 400 potentiostat (Ensman Instruments, Bloomington, IN) with provision for two working electrodes. A triangle wave $(-400$ to $1000 \mathrm{mV}$; $300 \mathrm{~V} / \mathrm{sec}$ scan rate) was applied every $100 \mathrm{msec}$. The bias potential between scans was $-400 \mathrm{mV}$. All potentials were referenced to a silversilver chloride electrode prepared by chloridizing $\sim 1 \mathrm{~mm}$ of an exposed silver wire coated with Teflon (30 gauge; World Precision Instruments, Sarasota, FL). The extracellular concentration of DA was obtained from the current at the peak oxidation potential for DA (typically 500-700 $\mathrm{mV}$ ) in successive voltammograms and converted to concentration on the basis of the calibration of each working electrode after the experiment in vitro. The calibration buffer consisted of $150 \mathrm{~mm}$ sodium chloride with 25 mM HEPES, pH 7.4, which, because no divalent cations are present, underestimates DA concentration by a factor of two to three according to Kume-Kick and Rice (1998) and our own determinations (data not shown). However, the process of removing the working electrode from the brain after the experiment leads to overestimating the calibration factor by a similar amount (Logman et al., 2000); thus no adjustment was made. Background-subtracted cyclic voltammograms were obtained by subtracting voltammograms collected during stimulation from those collected during baseline recording. All recordings used for this study exhibited voltammograms for DA (data not shown). The analog output of the potentiostat was digitized (Labmaster; Scientific Solutions, Solon, $\mathrm{OH})$ and stored to computer files using locally written software.

Experimental design. Two experimental designs were used in the present study. The first design, which consisted of three experimental groups, examined the acute effects of uptake inhibition. After a frequency response was collected in naive animals, either cocaine $(40$ $\mathrm{mg} / \mathrm{kg}$ ), nomifensine $(10 \mathrm{mg} / \mathrm{kg})$, or saline ( $150 \mathrm{~mm}$ sodium chloride; 1 $\mathrm{ml}$ ), was administered intraperitoneally. A second frequency response, identical to the first, was collected beginning 20 min later. This design allows each rat to serve as its own control when the effects of drugs are normalized to responses collected immediately before drug administration. Doses of cocaine and nomifensine, a competitive inhibitor of DA uptake (Tuomisto, 1977; Gianutsos et al., 1982; Jones et al., 1995a), were selected to obtain large but similar increases in evoked extracellular DA (Garris and Wightman, 1995a) to advance analysis. As shown (see Figs. $1,2,4)$, the desired effects were achieved. The effects of RTI-76 were examined with the second experimental design. Because RTI-76 was used in the present study as a noncompetitive inhibitor of DA uptake (Fleckenstein et al., 1996; Wang et al., 2000), it was necessary to perform the voltammetric experiment either 1 or $2 \mathrm{~d}$ after drug administration. As a result, predrug data are not available.

Kinetic analysis. Rate constants for DA release and uptake were determined from voltammetric recordings of electrically evoked levels of DA according to Jones et al. (Jones et al., 1995b). This procedure uses a set of equations describing the rate of change of extracellular DA $(\mathrm{d}[\mathrm{DA}] / \mathrm{d} t)$ as a balance between release and uptake (Wightman et al., 1988). During electrical stimulation:

$$
\mathrm{d}[\mathrm{DA}] / \mathrm{d} t=[\mathrm{DA}]_{\mathrm{p}} * f-V_{\max } /\left(K_{\mathrm{m}} /[\mathrm{DA}]_{\mathrm{EC}}+1\right),
$$

where $[\mathrm{DA}]_{\mathrm{p}}$ is the concentration of DA released per stimulus pulse, $f$ is the stimulus frequency, $V_{\max }$ and $K_{\mathrm{m}}$ are Michaelis-Menten rate constants for DA uptake, and [DA $]_{E C}$ is the extracellular concentration of DA. After cessation of the stimulus train, DA is cleared from extracellular space solely by the process of DA uptake:

$$
\mathrm{d}[\mathrm{DA}] / \mathrm{d} t=-V_{\max } /\left(K_{\mathrm{m}} /[\mathrm{DA}]_{\mathrm{EC}}+1\right) .
$$

The parameters $[\mathrm{DA}]_{\mathrm{p}}, V_{\max }$, and $K_{\mathrm{m}}$ were determined by fitting the entire frequency response $(10-60 \mathrm{~Hz})$ to Equations 1 and 2 . The fitting algorithm was a three-dimensional simplex minimization (Press et al., 1989), and goodness of fit was described by a regression coefficient $(r)$. The kinetic analysis was modified for evaluating the effects of RTI-76 (see Table 2). In this procedure $[\mathrm{DA}]_{\mathrm{p}}$ was calculated with the simplex algorithm after fixing $K_{\mathrm{m}}$ to the value obtained during predrug recording (see Table 1 ) and $V_{\max }$ to the value obtained from the initial clearance rate of extracellular DA measured from a $60 \mathrm{~Hz}$ response. At the high concentrations, at which extracellular levels of DA $\gg K_{\mathrm{m}}$, Equation 2 becomes:

$$
V_{\max }=-\mathrm{d}[\mathrm{DA}] / \mathrm{d} t \text {. }
$$

Statistical analysis. Where applicable, data are expressed as the mean \pm $\mathrm{SEM}$, and $n$ is the number of animals. Statistical analysis was performed by SAS (SAS Institute, Cary, NC) and used either a $t$ test or ANOVA. 

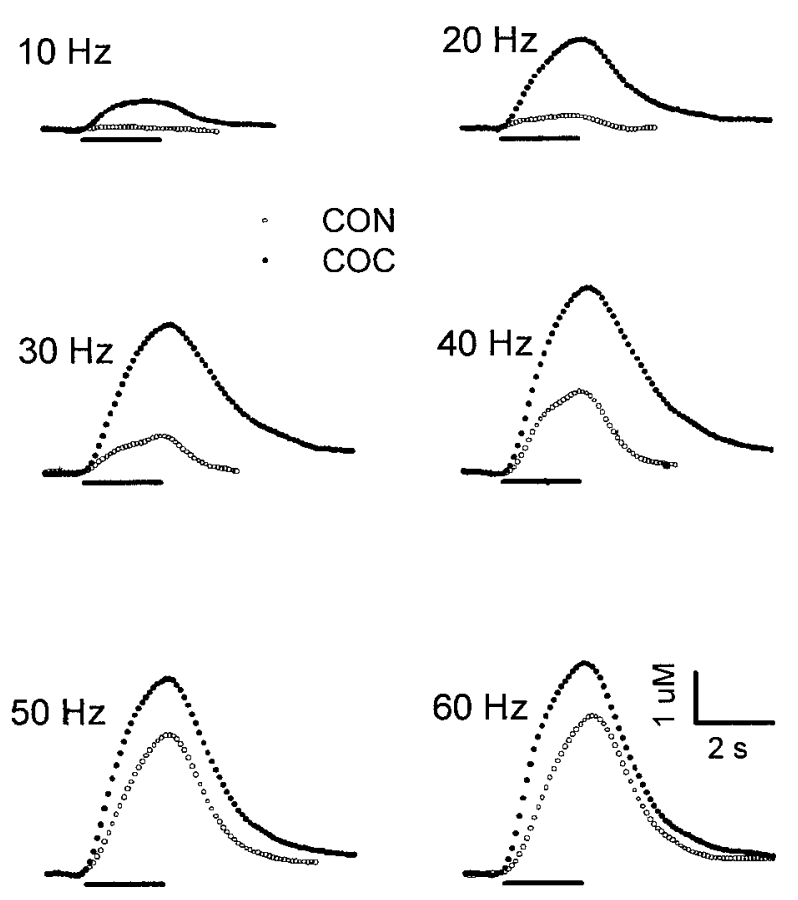

Figure 1. Effects of cocaine on electrically evoked levels of extracellular DA in the NAc. Changes in the dopamine signal were recorded during the predrug control phase (CON; open circles) and after administration of cocaine (COC; solid circles). All data are from the same animal. After collection of the predrug frequency response, cocaine $(40 \mathrm{mg} / \mathrm{kg}$, i.p.) was administered, and beginning 20 min later, a second frequency response using identical stimulus parameters was collected. Single points represent the concentration of DA determined at $100 \mathrm{msec}$ intervals during each voltammogram. Each pair of evoked signals was measured at the same stimulus frequency, shown on the top left of the traces. The solid line underneath each pair of recordings demarcates the time and duration of the stimulus train. For comparison, time and concentration scales and presentation of data are identical in this and subsequent figures (see Figs. $2,3)$.

When appropriate pair-wise comparisons of means were analyzed by the method of Tukey-Kramer. SigmaPlot (Jandel Corporation) calculated linear regression (see Fig. 8). The significance of $r$ was determined by calculating a $t$ statistic $\left(t_{\mathrm{s}}\right)$ :

$$
t_{\mathrm{s}}=r\left[(n-2) /\left(1-r^{2}\right)\right]^{1 / 2},
$$

where $n$ is the sample size (Sokal and Rohlf, 1995). The significance level was set at $p<0.05$ for all comparisons.

Drugs and reagents. All chemicals were used as received. RTI-76 was synthesized at Research Triangle Institute (Research Triangle Park, NC). Nomifensine maleate was purchased from Research Biochemicals (Natick, MA). Cocaine, sodium chloride, and HEPES were purchased from Sigma (St. Louis, MO). All drugs for injection were dissolved in $0.9 \%$ saline. To aid in dissolution, the nomifensine solution was acidified. Intraperitoneal injection volumes were $<2 \mathrm{ml}$. Aqueous solutions were prepared in nanopure water (Barnstead/Thermolyne Corporation, Dubuque, IA).

\section{RESULTS}

\section{Representative effects of uptake inhibitors in the NAC}

The effects of the uptake inhibitors on individual voltammetric recordings of evoked extracellular DA in the NAc are shown in Figures 1,2, and 3. Results are representative of the experimental groups, and two sets of recordings are found in each figure. In all figures, open circles describe the frequency response collected in naive animals $(C O N)$. Administration of cocaine $(40 \mathrm{mg} / \mathrm{kg}$, i.p. $)$ elicited a robust increase in extracellular DA (COC; solid circles) in the NAc (Fig. 1). The increase in extracellular DA was not
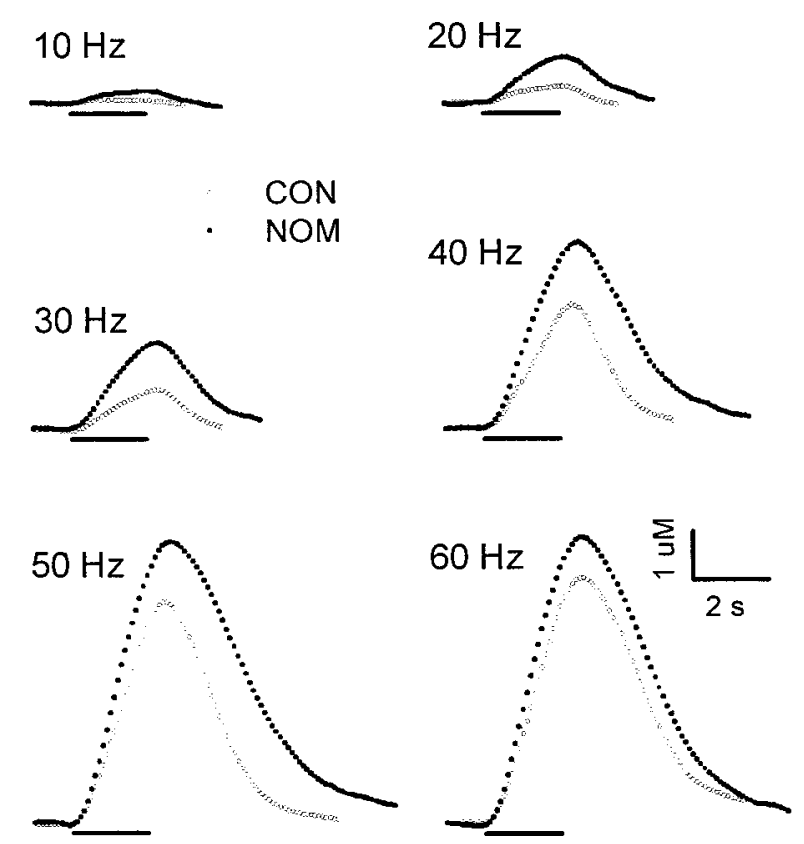

Figure 2. Effects of nomifensine on electrically evoked levels of extracellular DA in the NAc. Changes in the dopamine signal were recorded during the predrug control phase (CON; open circles) and after administration of nomifensine (NOM; solid circles). All data are from the same animal. The experimental design is identical for that used in Figure 1 except that nomifensine $(10 \mathrm{mg} / \mathrm{kg}$, i.p.) was administered.
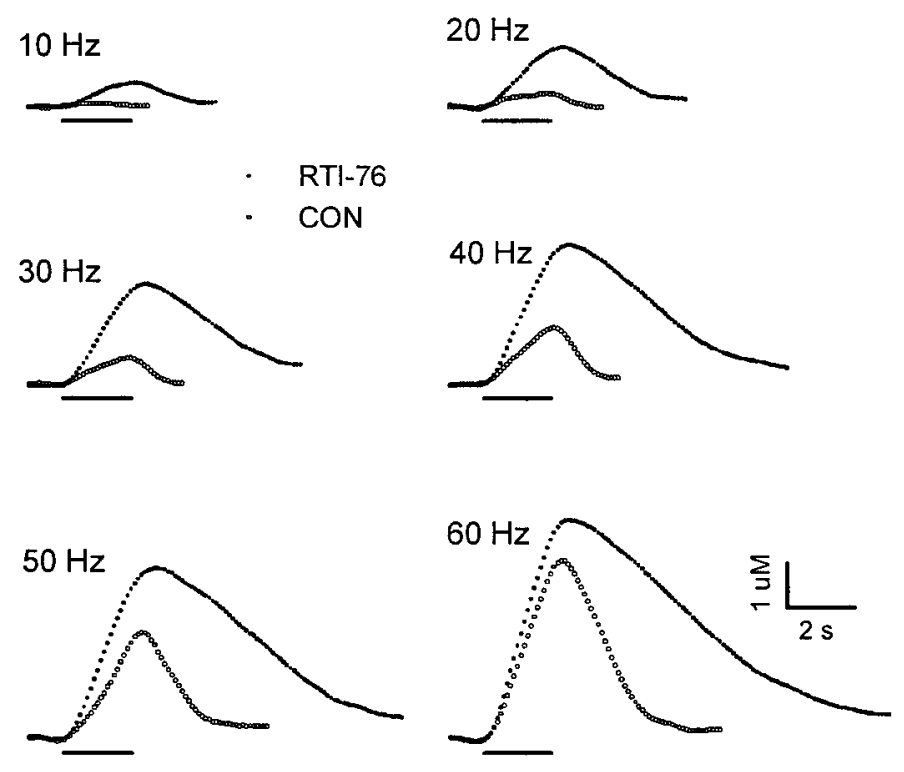

Figure 3. Effects of RTI-76 on electrically evoked levels of extracellular DA in the NAc. Two sets of evoked signals, recorded in different animals, are shown. The first set of traces describes changes in the dopamine signal monitored $1 \mathrm{~d}$ after intracerebroventricular injection of RTI-76 (100 $\mathrm{nmol}$; solid circles). The second set (CON; open circles) was recorded in a naive rat.

constant for each frequency, and cocaine appeared to have greater effects at lower frequencies. Cocaine, by and large, did not affect the overall shape of the evoked DA signals but rather scaled up responses. One interesting result of this phenomenon was that the extracellular clearance rate of DA evoked by electrical stimulation, shown previously to reflect $V_{\max }$ for DA uptake primarily 


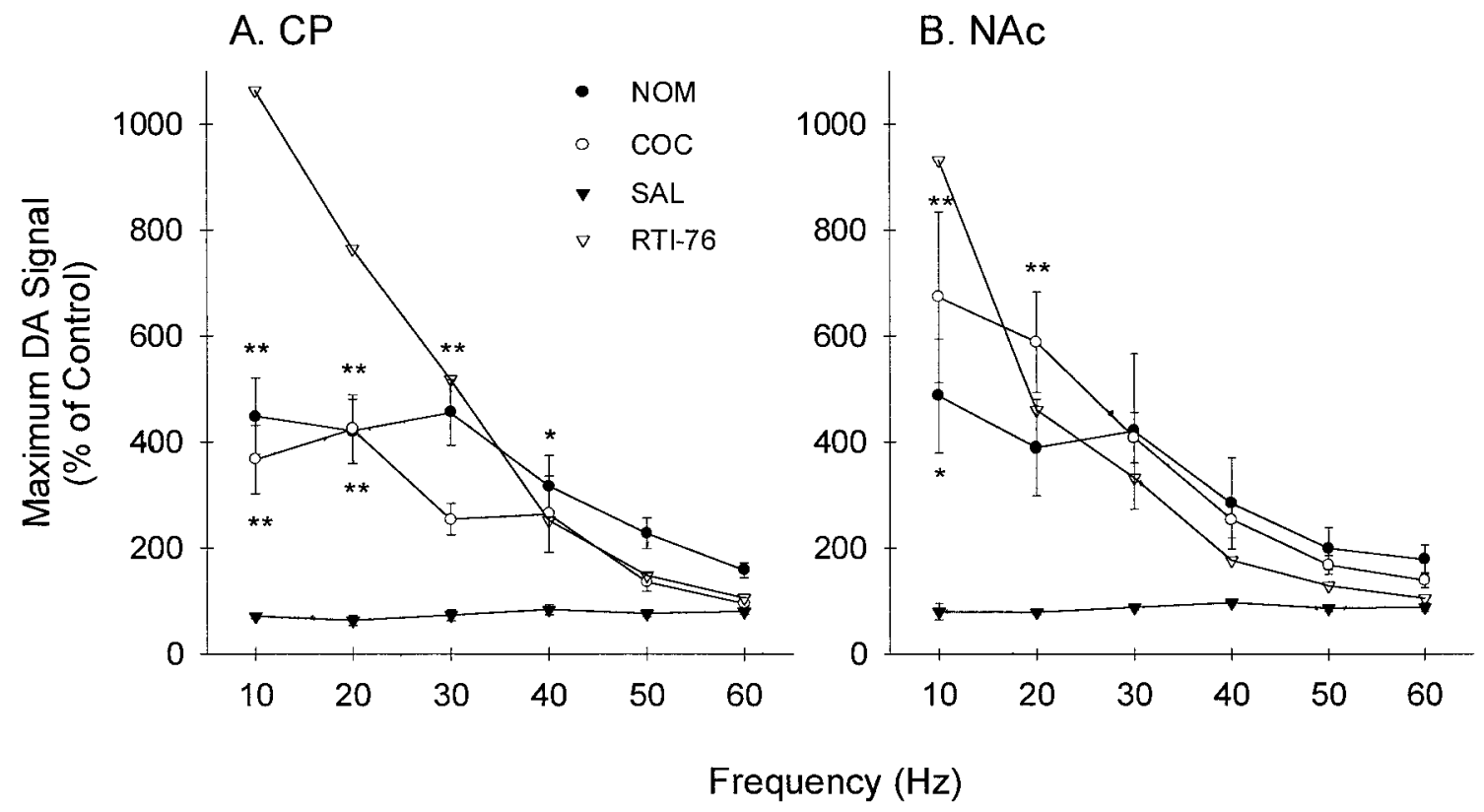

Figure 4. Average of the effects of uptake inhibitors on extracellular DA in the CP and NAc. The effects of nomifensine (NOM; solid circles), cocaine (COC; open circles), and saline (SAL; solid triangles) are expressed as a percentage of the predrug control and were calculated by dividing the maximal signal evoked in the presence of the inhibitor by the maximal signal measured during the control. After multiplying by 100 , values (\% of predrug control) were averaged for all animals and expressed as the mean $\pm \operatorname{SEM}(n=5-7)$. The effects of RTI-76 (open triangles) were calculated as a percentage of the predrug values averaged for the cocaine, saline, and nomifensine groups. $A, B$, Data collected in the CP and NAc, respectively. Statistical analysis only applies to the effects of cocaine and nomifensine relative to saline $\left({ }^{*} p<0.05 ;{ }^{*} p<0.01\right)$.

(see Eq. 3) (Wightman et al., 1988), was not markedly affected by cocaine. In fact, the portion of the evoked response describing the clearance of extracellular DA was essentially parallel to the predrug response at high concentrations $(>1 \mu \mathrm{M})$.

Figure 2 shows the effects of nomifensine $(10 \mathrm{mg} / \mathrm{kg}$, i.p. $)$ on extracellular DA (NOM; solid circles). In many respects the effects of nomifensine and cocaine were very similar. Nomifensine elicited robust increases in extracellular DA compared with control and was more effective in increasing DA levels elicited by lower frequencies. Moreover, nomifensine appeared to scale up evoked responses, which resulted in essentially parallel clearance curves in control and after nomifensine at high DA concentrations. Individual voltammetric recordings showing the effects of RTI-76 (solid circles) are shown in Figure 3. RTI-76 (100 nmol) was injected intracerebroventricularly $1 \mathrm{~d}$ before the voltammetric experiment. The effects of RTI-76 on the DA signals were striking. Similar to cocaine and nomifensine, RTI-76 robustly increased extracellular DA, an effect that was most pronounced at low frequencies. However, there were profound differences between the uptake inhibitors. In sharp contrast to cocaine and nomifensine, which scaled up evoked DA responses, RTI-76 changed the overall shape of the response. An even more prominent effect occurred immediately after high-frequency stimulation, when RTI-76 dramatically slowed the extracellular clearance rate of DA. Simultaneous recordings were collected in the $\mathrm{CP}$ in all animals shown representatively in Figures 1-3 (data not shown).

\section{Averaged effects of uptake inhibitors in the CP and NAc}

The averaged effects of the uptake inhibitors on extracellular DA in the $\mathrm{CP}$ and NAc are shown in Figure $4, A$ and $B$, respectively. To construct this figure, data from all animals shown representatively in Figures 1-3 and in the CP (data not shown) were compiled and expressed as a percentage of control. For nomifensine (NOM; solid circles) and cocaine (COC; open circles), the control was predrug recordings collected in each animal. A group of saline-injected animals is also shown ( $S A L$; solid triangles). These data were not described representatively but were treated identically. Saline did not appreciably affect extracellular DA, indicating that electrically evoked responses are stable over the experiment. The averaged results demonstrated that cocaine and nomifensine robustly increased extracellular DA in the two regions. The greater effect of the uptake inhibitors at low frequencies was readily apparent, and there was a significant effect of frequency in the $\mathrm{CP}\left(F_{(2,5)}=10.86 ; p<0.05\right)$ and NAc $\left(F_{(2,5)}=\right.$ $6.92 ; p<0.05)$. Typically, the effects of cocaine and nomifensine were maximal at 10 and $20 \mathrm{~Hz}$, began to decrease at $30 \mathrm{~Hz}$, and continued to decrease as frequency increased.

Although both cocaine and nomifensine significantly increased extracellular DA levels in the CP $(p<0.0001)$ and NAc $(p<$ $0.0001)$, the efficacy of uptake inhibitors appeared to differ between the regions. Whereas the effects of nomifensine were significantly greater than those of cocaine in the CP $(p<0.001)$, the uptake inhibitors were not significantly different from each other in the NAc. These regional differences in uptake inhibitors appeared to be caused by a greater effect of cocaine in the NAc compared with the CP rather than by differences in the effects of nomifensine. To test this possibility, data were analyzed to compare regional effects directly. Indeed, cocaine effects were significantly greater in the NAc than in the $\mathrm{CP}\left(F_{(1,5)}=6.76 ; p<0.01\right)$, but nomifensine effects were similar in the two regions. Furthermore, the cocaine-induced increase in extracellular DA evoked by $10 \mathrm{~Hz}$ was 1.8 -fold greater in the NAc, an enhancement similar in magnitude to previous reports describing the preferential effects of cocaine on DA neurons innervating this region compared 


Table 1. Parameters for DA release and uptake in the CP and NAc
\begin{tabular}{lclll} 
Region & {$[\mathrm{DA}]_{\mathrm{p}}(\mathrm{nM})$} & $V_{\max }(\mu \mathrm{M} / \mathrm{sec})$ & $K_{\mathrm{m}}(\mu \mathrm{M})$ & $r$ \\
\hline $\mathrm{CP}$ & $116 \pm 11$ & $5.18 \pm 0.58$ & $0.16 \pm 0.02$ & 0.957 \\
NAc & $78 \pm 9^{*}$ & $2.85 \pm 0.33^{* *}$ & $0.17 \pm 0.03$ & 0.927
\end{tabular}

Data are the mean $\pm \operatorname{SEM}(n=15-17)$.

${ }^{*} p<0.05 ;{ }^{* *} p<0.01$ (compared with value in the CP).

with the CP (Carboni et al., 1989; Cass et al., 1992, 1993; Kuczenski and Segal, 1992).

Because predrug recordings were not available for the experiment with RTI-76, a control group was created by combining all predrug values for cocaine, nomifensine, and saline. An average percentage of control was then calculated using the averaged predrug results and the averaged effects of RTI-76. These results represented by the open triangles in Figure 4 clearly showed that RTI-76 exhibited a different frequency response than did either cocaine or nomifensine. For example, in both the CP and NAc, RTI-76 increased extracellular DA to the greatest level at $10 \mathrm{~Hz}$, the lowest frequency, but to the lowest level or near the lowest level at $60 \mathrm{~Hz}$, the highest frequency. Although the lack of an error term precluded statistical analysis, observed differences in the frequency responses suggest that the mechanism of RTI-76 differs from that of both cocaine and nomifensine. There also appeared to be a greater effect of RTI-76 in the CP compared with the NAc.

\section{Kinetic analysis of the effects of uptake inhibitors}

Individual responses describing the dynamic changes in extracellular DA were analyzed to determine parameters for DA release and uptake. No restrictions were placed on calculating the three parameters $[\mathrm{DA}]_{\mathrm{p}}, V_{\max }$, and $K_{\mathrm{m}}$ from signals obtained in naive animals or after cocaine and nomifensine administration. This analysis differed from previous treatment of the increases in electrically evoked levels of DA induced by the uptake inhibitors that assumed a competitive mechanism on the basis of the shape of the clearance curve and fixed the $V_{\max }$ at control levels (Jones et al., 1995a). As a result, the analysis used in the present study to evaluate the effects of cocaine and nomifensine is more rigorous because no a priori assumptions are made about the inhibitory mechanism. Average values for parameters calculated from all predrug recordings in naive animals are shown in Table 1. Both [DA $]_{\mathrm{p}}$ and $V_{\max }$ were significantly greater in the CP compared with the NAc $(p<0.02$ and $<0.002$, respectively). In contrast, $K_{\mathrm{m}}$ was not statistically different in these regions and was high affinity $(\approx 0.2 \mu \mathrm{M})$. Overall, these values are in excellent agreement with previous reports (Garris and Wightman, 1994; Jones et al., 1995b).

The analysis of curves collected after administration of cocaine and nomifensine is shown in Figure 5. The results clearly demonstrated that increases in extracellular DA after systemic cocaine $(C O C)$ or nomifensine $(N O M)$ are associated with an increase in $K_{\mathrm{m}}$ but not a change in $V_{\max }$ or $[\mathrm{DA}]_{\mathrm{p}}$. In the $\mathrm{CP}$, increases in $K_{\mathrm{m}}$ elicited by cocaine and nomifensine were similar and robust $(11.0 \pm 2.0$ and $12.8 \pm 2.12$, respectively $)$ and significantly different from that of saline $(S A L ; p<0.01$ and 0.003 , respectively). The effect of cocaine on $K_{\mathrm{m}}$ in the NAc $(10.0 \pm 1.9)$ was similar to that in the $\mathrm{CP}$ and was also significantly different from that of saline $(p<0.002)$. In contrast, the effect of nomifensine on $K_{\mathrm{m}}(4.2 \pm 1.0)$ in the NAc was not significantly different from that of saline. These results are in excellent agree-

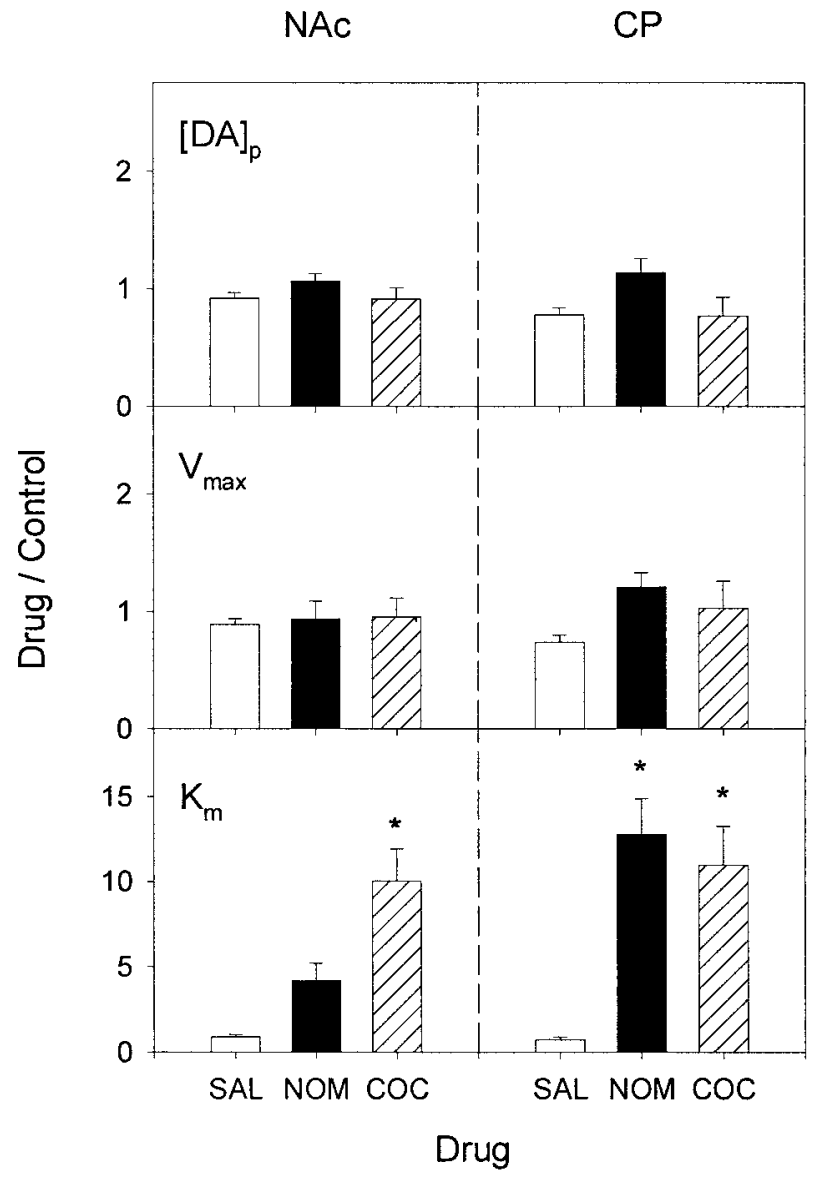

Figure 5. Analysis of the effects of nomifensine and cocaine on DA release and uptake in the CP and NAc. Recordings describing the effects of cocaine, nomifensine, and saline on electrically evoked levels of DA were kinetically analyzed to determine parameters for DA release and uptake. Resulting changes in $[\mathrm{DA}]_{\mathrm{p}}, V_{\max }$, and $K_{\mathrm{m}}$ are expressed as the ratio of drug to predrug values. All data are the mean $\pm \operatorname{SEM}(n=5-7)$. Results in the NAc and CP are shown in left and right panels, respectively ( ${ }^{*} p<0.05$, compared with $S A L$ in each region). COC, Cocaine; $N O M$, nomifensine; $S A L$, saline.

Table 2. Effects of RTI-76 on DA release and uptake in the CP and NAc

\begin{tabular}{llll} 
Region & {$[\mathrm{DA}]_{\mathrm{p}}(\mathrm{nM})$} & $V_{\max }(\mu \mathrm{M} / \mathrm{sec})$ & $r$ \\
\hline $\mathrm{CP}$ & $50 \pm 8$ & $0.49 \pm 0.09$ & 0.902 \\
NAc & $41 \pm 8$ & $0.49 \pm 0.12$ & 0.914
\end{tabular}

All data are the mean $\pm \operatorname{SEM}(n=6-7)$.

ment with those of Jones et al. (1995a), who demonstrated that cocaine elicits a similar increase in $K_{\mathrm{m}}$ in the CP and NAc but that nomifensine is more potent in the former striatal region. There were also no significant differences between the effects of cocaine, nomifensine, and saline on $[\mathrm{DA}]_{\mathrm{p}}$ or $V_{\max }$ in either region (Fig. 5, top two rows of panels).

Analysis of the effects of RTI-76 on extracellular DA levels is shown in Table 2. When compared with parameters calculated in naive animals (Table 1), RTI-76 was found to decrease $V_{\max }$ significantly in both the CP $(p<0.0001, t$ test $)$ and NAc $(p<$ $0.01, t$ test $)$. The decrease was greater in the CP (10-fold) than in the NAc (5.5-fold). RTI-76 also significantly decreased [DA $]_{\mathrm{p}}$ in both regions ( $\mathrm{CP}, p<0.003$; NAc, $p<0.006, t$ test). Similar to 

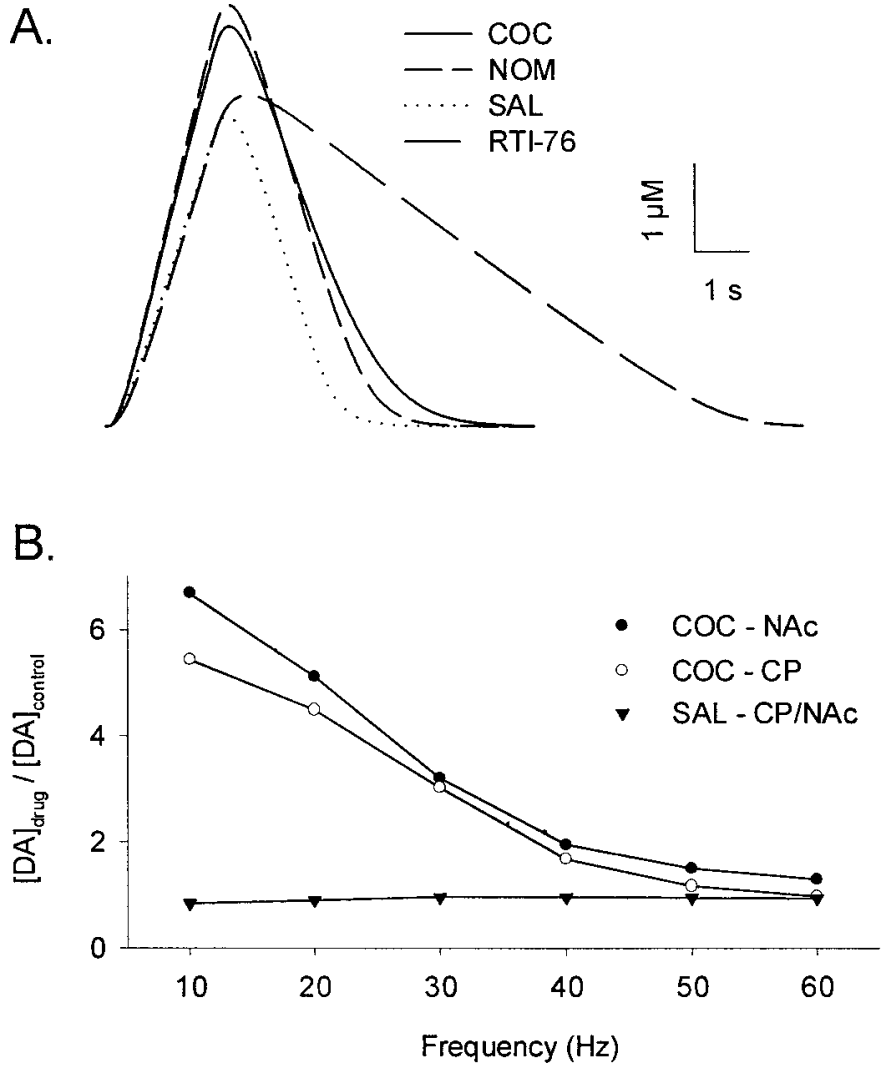

Figure 6. Simulated effects of uptake inhibitors on extracellular DA in the $\mathrm{CP}$ and NAC. To minimize variability in measured DA levels, a single group of control (i.e., predrug) curves was simulated using the average parameters for DA release and uptake found in Table 1. The effects of cocaine, nomifensine, and saline were then simulated after multiplying the control parameters by the ratio of drug to predrug effects found in Figure 5. Because no predrug responses were collected, the effects of RTI-76 were simulated directly using parameters found in Table 2. All simulated curves were calculated from Equations 1 and 2. $A$, Individual curves simulated for a frequency of $60 \mathrm{~Hz}$ in the NAc. The beginning of each curve is the initiation of the stimulus train. $B$, Simulated frequency responses for the effects of cocaine and saline. Simulated data are expressed as a ratio of drug over control values, identical to that for experimental data in Figure 4. The effects of cocaine are shown for both the NAc (solid circles; COC-NAc) and CP (open circles; COC-CP). The effects of saline in the two regions were averaged to produce a single frequency response (solid triangles; $S A L-C P / N A c$ ). COC, Cocaine; NOM, nomifensine; $S A L$, saline.

$V_{\text {max }}$, the decrease in DA release was greater in the CP (2.3-fold) compared with the NAc (1.5-fold).

To test the veracity of the kinetic analysis, responses were simulated using the calculated parameters for DA release and uptake. If accurate, the simulations will exhibit the unique features of extracellular DA dynamics after uptake inhibition. Responses simulated for $60 \mathrm{~Hz}$ stimulation are shown in Figure $6 \mathrm{~A}$. This frequency was selected because uptake inhibitor effects on initial clearance rates factored prominently in the representative experimental responses (Figs. 1-3). Simulated curves clearly described the distinguishing characteristic of RTI-76, the marked decrease in the initial clearance rate of evoked extracellular DA. In contrast, initial clearance rates after either cocaine or nomifensine administration were primarily unaffected. Simulations of low-frequency responses using altered uptake kinetics but without any change in the DA release term also reflected the robust increase in evoked extracellular DA present in the experimental data (data not shown). In addition to individual voltammetric responses, averaged results describing cocaine effects are simulated with a high degree of fidelity as shown in Figure $6 \mathrm{~B}$. In excellent agreement with experimental results, there was an inverse relationship between frequency and the relative increase in extracellular DA after cocaine administration. Most important, simulations reflected the preferential increase in extracellular DA in the NAc compared with the CP.

\section{Relationship of uptake inhibitor effects to DA release and uptake rates}

Theoretical calculations were used to test the hypothesis postulated by Cass et al. (1992) that a lower number of DA uptake sites in the NAc is responsible for the preferential increase in extracellular DA after cocaine administration. These calculations are shown in Figure 7. To cover the range of stimulation frequencies in the experiments, $20 \mathrm{~Hz}$ (left panels) and $60 \mathrm{~Hz}$ (right panels) pulse trains were used. Responses modeling the effects of cocaine in the NAc are shown in Figure $7 A$. By substituting the $V_{\max }$ determined in the $\mathrm{CP}$, curves shown in Figure $7 B$ modeled the effects of cocaine for the condition of a higher number of uptake sites. If a low $V_{\max }$ is responsible for the greater effect of cocaine in the NAc, then a high $V_{\max }$ should reverse or reduce it. On the contrary, the theoretical calculations demonstrated that a higher $V_{\max }$ in the NAc by itself would actually enhance the effects of cocaine on extracellular DA.

We next examined the relationships between the relative increase in extracellular DA after uptake inhibition and rates for DA release and uptake. For this analysis shown in Figure 8, the effects of cocaine in the $\mathrm{CP}$ and NAc and nomifensine in the CP were combined to obtain a reasonable number of points for regression. Combining these data was justified on the basis that the uptake blockers exhibited a similar mechanism and efficacy of inhibition in the two regions (Fig. 5) (Jones et al., 1995a). Similarly, the effects of nomifensine in the NAc were excluded on the basis of a lower efficacy (Fig. 5) (Jones et al., 1995a). There appeared to be an inverse relationship between $[\mathrm{DA}]_{\mathrm{p}}$ (Fig. 8A) or $V_{\max }$ (Fig. $8 B$ ) and increases in extracellular DA, and linear regression demonstrated a significant relationship between these parameters and drug effect $(r=0.837$; $p<0.01$; and $r=0.777$; $p<0.01$, respectively). Additionally, averaged values for $[\mathrm{DA}]_{\mathrm{p}}$ and $V_{\max }$ laid along the regression lines. The relationship between the rates for DA release and uptake in the $\mathrm{CP}$ and NAc are show in Figure $8 C$. All predrug data were combined for this analysis that showed a linear relationship between $[\mathrm{DA}]_{\mathrm{p}}$ and $V_{\max }(r=$ 0.904; $p<0.001)$.

\section{DISCUSSION}

\section{Mechanism of cocaine}

Because there is a great discrepancy in the mechanism reported for cocaine inhibiting striatal DA uptake (see introductory remarks), a three-pronged approach was used in the present study to assess the kinetics: (1) comparison of cocaine with two other blockers of DA uptake (nomifensine, a competitive inhibitor, and RTI-76, a noncompetitive inhibitor), (2) qualitative evaluation of the effects of cocaine on the dynamic changes in extracellular DA, and (3) quantitative analysis of these DA changes. Inspection of the individual recordings of extracellular DA clearly indicated that cocaine acts similar to nomifensine but different from RTI-76 in vivo (Figs. 1-3). Indeed, in contrast to the other inhibitors, RTI-76 dramatically slowed the clearance of evoked extracellular DA and altered the overall dynamics of the signals. The effects on 


\section{A. NAc - Control}
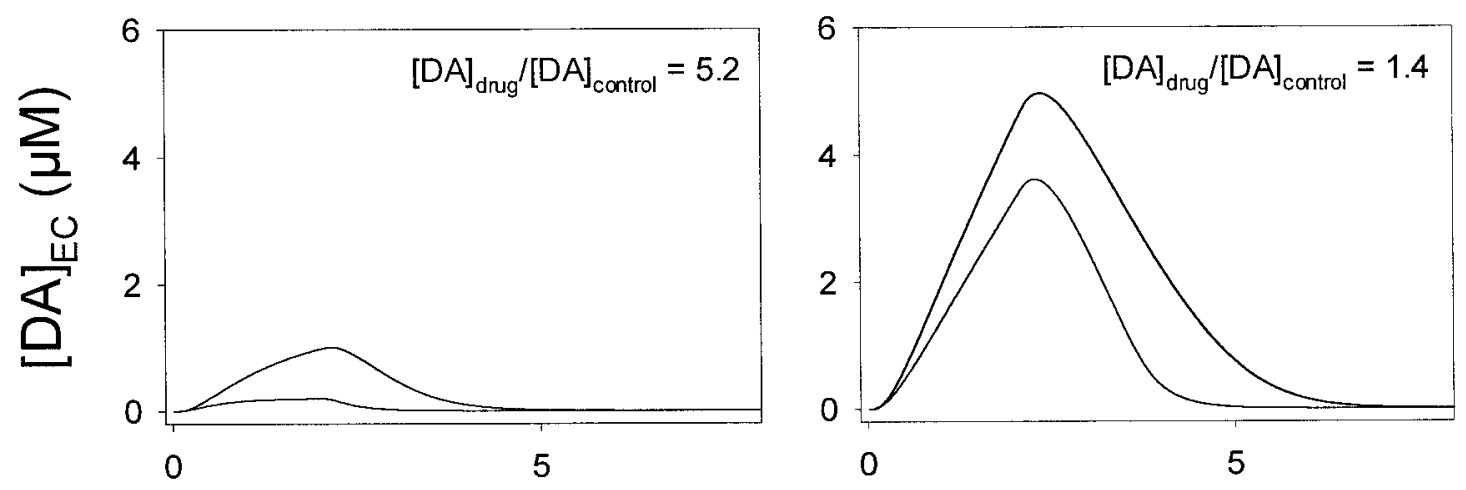

\section{B. "NAc" - High Uptake}

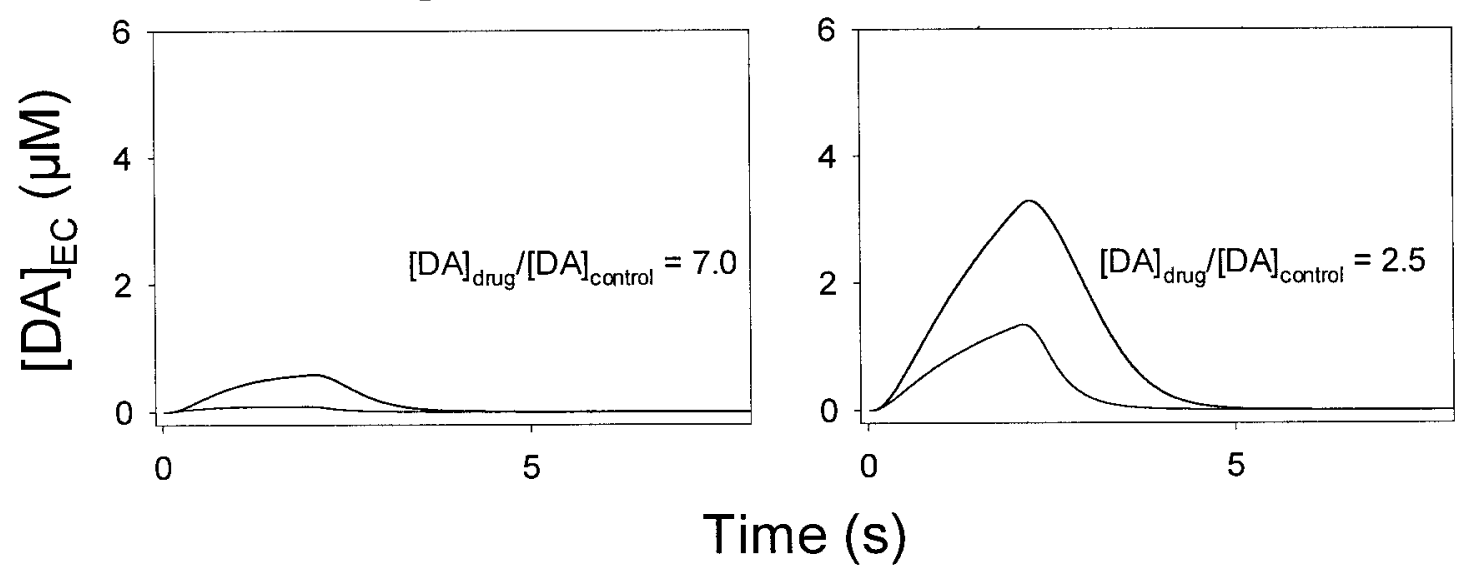

Figure 7. Theoretical effects of altering the $V_{\max }$ for DA uptake on cocaine-induced increases of extracellular DA in the NAc. Theoretical responses to 20 and $60 \mathrm{~Hz}$ stimulation are shown in left and right panels, respectively. Each panel contains two sets of curves, one for predrug control and the other for cocaine. In all panels the curve with the higher amplitude is the cocaine curve. The ratio of drug over control for maximal levels of extracellular DA, calculated as in Figure 4, is shown in each panel ([DA $]_{\text {drug }} /[\mathrm{DA}]_{\text {control }}$ ). All curves were calculated from Equations 1 and 2 . A, The simulated effects of cocaine in the NAc. $B$, The theoretical effects of cocaine in the "NAc" when the $V_{\max }$ for DA uptake is increased to resemble that of the CP. $E C$, Extracellular.

clearance are especially revealing with regard to inhibitory mechanism, because at high DA concentrations the transporter is saturated and uptake rates directly reflect $V_{\max }$ (Eq. 3) (Wightman et al., 1988). Thus, the dominant effect of RTI-76 on DA dynamics was a decrease in $V_{\max }$, which is consistent with the quantitative analysis of the evoked DA signals (Table 2) and binding and uptake assays (Fleckenstein et al., 1996; Wang et al., 2000).

Neither cocaine nor nomifensine slowed initial clearance rates for extracellular DA, as demonstrated by the nearly parallel predrug and postdrug curves, suggesting that $V_{\max }$ was unaltered. These uptake inhibitors were, therefore, acting via a change in $K_{\mathrm{m}}$ or DA release to increase levels of electrically evoked DA. Quantitative analysis indicated that drug effects were mediated solely by an increase in $K_{\mathrm{m}}$ (Fig. 5), which manifests as an increase in the inflection point of the clearance curve (Wightman and Zimmerman, 1990; Garris and Wightman, 1994). Although a change in inflection point was not obvious in experimental and simulated (Figs. 1, 6, 7) responses, Jones et al. (1995a) found that large increases in $K_{\mathrm{m}}$, much greater $(\approx 50$-fold) than those in the present study, are required before this effect is prominent.

Taken together, the combined analysis suggests that competi- tive inhibition of the DA transporter is the primary neurochemical effect mediating the observed cocaine-induced increases in the levels of electrically evoked DA. This conclusion is consistent with some but not all studies evaluating a mechanism for cocaine (see introductory remarks). An explanation of these discrepancies is not readily available. On the basis of a literature review and results obtained with the rotating disk electrode in vitro, Schenk and coworkers (Povlock et al., 1996) cogently argue that kinetics for DA uptake varies with experimental conditions. Whether this phenomenon is related to the discrepancies concerning the mechanism of cocaine is not known. The kinetic effects of cocaine on DA uptake have been extensively studied in vitro by $\left[{ }^{3} \mathrm{H}\right] \mathrm{dopam}-$ ine uptake into synaptosomes, and comparing such results with those obtained by in vivo voltammetry is not straightforward (Rice and Nicholson, 1995; Zahniser et al., 1999). However, the present results agree favorably with those of Jones et al. (1995a) using voltammetry and electrical stimulation in slices. Differences between in vitro and in vivo conditions, thus, may be less important. In the present study the effects of inhibitors on extracellular DA and DA uptake were determined from the same measurements (Wightman et al., 1988), minimizing complications arising from comparisons across experimental procedures. Moreover, 
A.

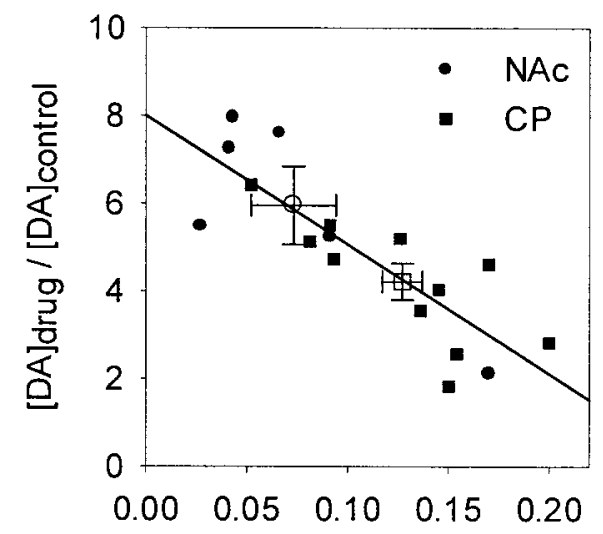

B.

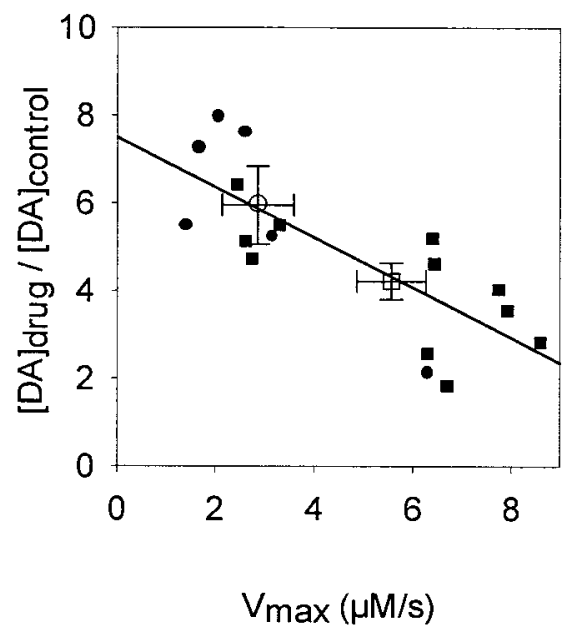

C.

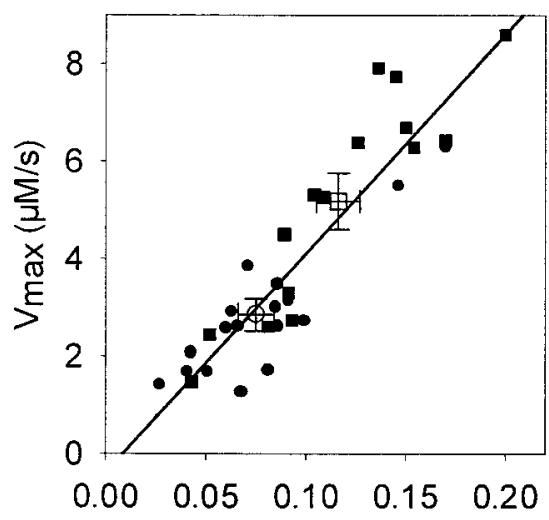

$[\mathrm{DA}] \mathrm{p}(\mu \mathrm{M})$

Figure 8. A, B, Functional relationships between the effects of uptake inhibition on extracellular DA and $[\mathrm{DA}]_{\mathrm{p}}$ or $V_{\max }$, respectively. Data are from the 17 animals in which the effects of cocaine in the CP and NAc and nomifensine in the NAc were analyzed. Increases in DA levels after administration of uptake inhibitors are expressed as the ratio of drug over control and calculated for a frequency of $20 \mathrm{~Hz}$. $C$, The functional relationship between [DA $]_{\mathrm{p}}$ and $V_{\max }$. Data are from 31 animals and represent all predrug data found in this study. In all panels, solid symbols are individual values, and open symbols are average values (error bars indicate SEM). Squares and circles represent data in the CP and NAc, respectively. Solid lines were calculated by linear regression.

the kinetic analysis made no assumptions about the inhibitory mechanism of cocaine.

\section{Inhibitor effects and DA neurotransmission}

The present study links for the first time an entire set of parameters describing rates for not only DA release but also uptake to the effects of uptake inhibitors on extracellular DA levels in the $\mathrm{CP}$ and NAc. The relationship is best depicted in Figure 8 that shows an inverse correlation between inhibitor-induced increases in extracellular DA levels and $[\mathrm{DA}]_{\mathrm{p}}$, a rate constant for dopamine release, and $V_{\text {max }}$, which is proportional to the number of DA uptake sites. The results also connect the preferential effects of the uptake inhibitors to DA release and uptake rates in the NAc that are on average lower than those in the CP. The preferential effects are not exclusive to the striatal region, however, because rates overlap considerably in the NAc and CP as shown in Figure $8 C$ and previously by others (Stamford et al., 1986; May and Wightman, 1989; Garris et al., 1994). Indeed, recording sites in the $\mathrm{CP}$ supporting DA release and uptake rates that are lower than values averaged in the NAc also exhibited greater inhibitor effects on extracellular DA and vice versa.

The observed correlation between DA release and uptake inhibitor effects is surprising because a direct action of the drugs on release is not indicated by the kinetic analysis (Fig. 5). An indirect link is possible because the rate of DA uptake is concentration dependent and brain extracellular levels of DA are determined by the balance between DA release and uptake processes (Wightman et al., 1988). Because of the particular combination of DA release and uptake, moreover, greater levels of DA are electrically evoked in the NAc compared with the CP (Garris et al., 1994). Thus, we speculate that, because of higher concentrations of extracellular DA, transporters in the NAc are more readily saturated after uptake inhibition, which leads to enhanced drug effects. A similar mechanism may also support the preferential increases in dialysate DA.

\section{Preferential effects of cocaine on accumbal DA}

Several studies including the present demonstrate that systemic administration of cocaine increases extracellular DA levels to a greater extent in the NAc than in the CP (Fig. 4) (Carboni et al., 1989; Cass et al., 1992, 1993; Kuczenski and Segal, 1992). We hypothesize that a mechanism other than a specific interaction between cocaine and the DA transporter mediates the preferential effects of psychostimulant. This postulate is based on our finding that cocaine inhibits DA uptake in both the CP and NAc by a competitive mechanism in vivo and the similar efficacy for cocaine binding to the DA transporter and inhibiting DA uptake (Fig. 5) (Boja and Kuhar, 1989; Izenwasser et al., 1990; Cass et al., 1992; Jones et al., 1995a). Our hypothesis states that the preferential increase in accumbal DA is related to the unique presynaptic regulation of extracellular DA in this region. The present results clearly demonstrated that rates for DA release and uptake are negatively correlated to inhibitor-induced increases in extracellular DA and are lower on average in the NAc compared with the CP. Consequently, we propose that the lower rates for DA release and uptake in the NAc produce a greater effect of cocaine on extracellular DA. Although striatal rates for DA release and uptake are directly related to innervation density, rates in the cortex and amygdala are not [i.e., $[\mathrm{DA}]_{\mathrm{p}}$ and $V_{\max }$ would not lie on the same regression line in Fig. 8C (see Garris et al., 1994)]. Thus, the presynaptic regulation of dopamine in the NAc is unlike that of all brain regions assessed in this manner. Our postulate is in partial agreement with Cass et al. (1992), who hypothesized that only DA uptake is involved. However, the calculations shown in Figure 7 suggest that regional differences in $V_{\max }$ are not the sole factor. Additionally, the responses modeled in Figure 6 demonstrated that the lower rates for DA release and uptake measured in the NAc are sufficient to increase extracellular DA to a greater extent than in the CP.

Cocaine effects in other regions may also be related to the set of release and uptake parameters describing the prevailing pre- 
synaptic control of DA. Interestingly, the reduced effectiveness of cocaine to increase extracellular DA in the amygdala and prefrontal cortex (Moghaddam and Bunney, 1989; Garris and Wightman, 1995a; Hurd et al., 1997) is associated with unusually slow rates for DA uptake and high rates for DA release, respectively (Garris and Wightman, 1994; Jones et al., 1995b). Systemic administration of cocaine has also been shown to increase extracellular DA to a greater extent in the NAc shell compared with the core (Pontieri et al., 1995; David et al., 1998). Although results from in vitro voltammetry indicate that rates for DA release and uptake are proportionally lower in the shell (Jones et al., 1996), consistent with our hypothesis, it is necessary to apply the present in vivo analysis to this region to determine whether the regression lines shown in Figure 8 are extended to lower rates. Nevertheless, the combination and magnitude of DA uptake and release rates appear to be critical for the preferential effects of cocaine on extracellular DA in the brain.

Because amphetamine and nomifensine increase dialysate DA to a greater extent in the NAc than in the CP (Carboni et al., 1989; Cenci et al., 1992; Kuczenski and Segal, 1992), the presynaptic control of DA may also be involved in mediating the effects of inhibitors other than cocaine. However, this conclusion is stated cautiously because of the complex presynaptic action for amphetamine (Sulzer et al., 1995; Giros et al., 1996). Surprisingly, the preferential effect of nomifensine because of presynaptic DA control appears to overcome the lower potency for inhibiting DA uptake in the NAc compared with the CP (Jones et al., 1995a) but only for levels of basal DA estimated by microdialysis, not evoked DA monitored by voltammetry (Fig. 4). This finding suggests that differences between techniques for measuring DA should also be considered. The differential effects of RTI-76 in the striatum are confounded by the possibility that intracerebroventricular administration did not deliver a uniform dose. Certainly, other DA uptake inhibitors with a similar mechanism and potency in the CP and NAc should be evaluated to determine the importance of presynaptic DA control further.

\section{Conclusion}

This study demonstrates that the presynaptic control of extracellular DA by release and uptake processes is an important determinant for the effects of cocaine and perhaps other uptake inhibitors in the brain. Because rates for DA release and uptake extensively overlap, sites where cocaine exhibits its greatest relative increases in extracellular DA are heterogeneously distributed throughout the sensorimotor and limbic striatum. Although the importance of these DA changes to behavior remains to be determined, the present results suggest that cocaine potentially acts at many sites in this anatomically and functional diverse region because of the heterogeneity of DA release and uptake rates.

\section{REFERENCES}

Bergstrom BP, Garris PA (1999) Utility of a tripolar stimulating electrode for eliciting dopamine release in the rat striatum. J Neurosci Methods 87:201-208.

Bjorklund A, Lindvall O (1984) Dopamine-containing systems in the CNS. In: Handbook of chemical neuroanatomy (Bjorklund A, Hokfelt T, eds), pp 55-122. New York: Elsevier.

Boja JW, Kuhar MJ (1989) $\left[{ }^{3} \mathrm{H}\right]$ cocaine binding and inhibition of $\left[{ }^{3} \mathrm{H}\right]$ dopamine uptake is similar in both the rat striatum and nucleus accumbens. Eur J Pharmacol 173:215-217.

Bradberry CW, Barrett-Larimore RL, Jatlow P, Rubino SR (2000) Impact of self-administered cocaine and cocaine cues on extracellular dopamine in mesolimbic and sensorimotor striatum in rhesus monkeys. J Neurosci 20:3874-3883.

Cahill PS, Walker QD, Finnegan JM, Mickelson GE, Travis ER, Wight- man RM (1996) Microelectrodes for the measurement of catecholamines in biological systems. Anal Chem 68:3180-3186.

Cao CJ, Young MM, Wong JB, Mahran LG, Eldefrawi ME (1989) Putative cocaine receptor in striatum is a glycoprotein with active thiol function. Membr Biochem 8:207-220.

Carboni E, Imperato A, Perezzani L, Di Chiara G (1989) Amphetamine, cocaine, phencyclidine and nomifensine increase extracellular dopamine concentrations preferentially in the nucleus accumbens of freely moving rats. Neuroscience 28:653-661.

Cass WA, Gerhardt GA, Mayfield RD, Curella P, Zahniser NR (1992) Differences in dopamine clearance and diffusion in rat striatum and nucleus accumbens following systemic cocaine administration. J Neurochem 59:259-266.

Cass WA, Zahniser NR, Flach KA, Gerhardt GA (1993) Clearance of exogenous dopamine in rat dorsal striatum and nucleus accumbens: role of metabolism and effects of locally applied uptake inhibitors. J Neurochem 61:2269-2278.

Cenci MA, Kalen P, Mandel RJ, Bjorklund A (1992) Regional differences in the regulation of dopamine and noradrenaline release in medial frontal cortex, nucleus accumbens and caudate-putamen: a microdialysis study in the rat. Brain Res 581:217-228.

Cline EJ, Adams CE, Larson GA, Gerhardt GA, Zahniser NR (1995) Medial dorsal striatum is more sensitive than lateral dorsal striatum to cocaine inhibition of exogenous dopamine clearance: relation to $\left[{ }^{3} \mathrm{H}\right]$ mazindol binding, but not striosome/matrix. Exp Neurol 134:135-149.

Cragg SJ, Hille CJ, Greenfield SA (2000) Dopamine release and uptake dynamics within nonhuman primate striatum in vitro. J Neurosci 20:8209-8217.

David DJ, Zahniser NR, Hoffer BJ, Gerhardt GA (1998) In vivo electrochemical studies of dopamine clearance in subregions of rat nucleus accumbens: differential properties of the core and shell. Exp Neurol 153:277-286.

Fleckenstein AE, Pogun S, Carroll FI, Kuhar MJ (1996) Recovery of dopamine transporter binding and function after intrastriatal administration of the irreversible inhibitor RTI-76 [3 beta-( $3 p$-chlorophenyl) tropan-2 beta-carboxylic acid $p$-isothiocyanatophenylethyl ester hydrochloride]. J Pharmacol Exp Ther 279:200-206.

Garris PA, Wightman RM (1994) Different kinetics govern dopaminergic transmission in the amygdala, prefrontal cortex, and striatum: an in vivo voltammetric study. J Neurosci 14:442-450.

Garris PA, Wightman RM (1995a) Distinct pharmacological regulation of evoked dopamine efflux in the amygdala and striatum of the rat in vivo. Synapse 20:269-279.

Garris PA, Wightman RM (1995b) Regional differences in dopamine release, uptake, and diffusion measured by fast-scan cyclic voltammetry. In: Neuromethods: voltammetric methods in brain systems (Boulton A, Baker G, Adams RN, eds), pp 179-220. Totowa, NJ: Humana.

Garris PA, Ciolkowski EL, Wightman RM (1994) Heterogeneity of evoked dopamine overflow within the striatal and striatoamygdaloid regions. Neuroscience 59:417-427.

Garris PA, Walker QD, Wightman RM (1997) Dopamine release and uptake rates both decrease in the partially denervated striatum in proportion to the loss of dopamine terminals. Brain Res 753:225-234

Gianutsos G, Morrow G, Light S, Sweeney MJ (1982) Dopaminergic properties of nomifensine. Pharmacol Biochem Behav 17:951-954.

Giros B, Jaber M, Jones SR, Wightman RM, Caron MG (1996) Hyperlocomotion and indifference to cocaine and amphetamine in mice lacking the dopamine transporter. Nature 379:606-612.

Hurd YL, McGregor A, Ponten M (1997) In vivo amygdala dopamine levels modulate cocaine self-administration behaviour in the rat: D1 dopamine receptor involvement. Eur J Neurosci 9:2541-2548.

Izenwasser S, Werling LL, Cox BM (1990) Comparison of the effects of cocaine and other inhibitors of dopamine uptake in rat striatum, nucleus accumbens, olfactory tubercle, and medial prefrontal cortex. Brain Res 520:303-309.

Jones SR, Garris PA, Wightman RM (1995a) Different effects of cocaine and nomifensine on dopamine uptake in the caudate-putamen and nucleus accumbens. J Pharmacol Exp Ther 274:396-403.

Jones SR, Garris PA, Kilts CD, Wightman RM (1995b) Comparison of dopamine uptake in the basolateral amygdaloid nucleus, caudateputamen, and nucleus accumbens of the rat. $J$ Neurochem 64:2581-2589.

Jones SR, O’Dell SJ, Marshall JF, Wightman RM (1996) Functional and anatomical evidence for different dopamine dynamics in the core and shell of the nucleus accumbens in slices of rat brain. Synapse 23:224-231.

Kalivas PW, Nakamura M (1999) Neural systems for behavioral activation and reward. Curr Opin Neurobiol 9:223-227.

Koob GF, Bloom FE (1988) Cellular and molecular mechanisms of drug dependence. Science 242:715-723.

Krueger BK (1990) Kinetics and block of dopamine uptake in synaptosomes from rat caudate nucleus. J Neurochem 55:260-267.

Kuczenski R, Segal DS (1992) Differential effects of amphetamine and dopamine uptake blockers (cocaine, nomifensine) on caudate and ac- 
cumbens dialysate dopamine and 3-methoxytyramine. J Pharmacol Exp Ther 262:1085-1094.

Kuhar MJ, Ritz MC, Boja JW (1991) The dopamine hypothesis of the reinforcing properties of cocaine. Trends Neurosci 14:299-302.

Kume-Kick J, Rice ME (1998) Dependence of dopamine calibration factors on media $\mathrm{Ca}^{2+}$ and $\mathrm{Mg}^{2+}$ at carbon-fiber microelectrodes used with fast-scan cyclic voltammetry. J Neurosci Methods 84:55-62.

Logman MJ, Budygin EA, Gainetdinov RR, Wightman RM (2000) Quantitation of in vivo measurements with carbon fiber microelectrodes. J Neurosci Methods 95:95-102.

May LJ, Wightman RM (1989) Heterogeneity of stimulated dopamine overflow within rat striatum as observed with in vivo voltammetry. Brain Res 487:311-320.

McBride WJ, Murphy JM, Ikemoto S (1999) Localization of brain reinforcement mechanisms: intracranial self-administration and intracranial place-conditioning studies. Behav Brain Res 101:129-152.

McElvain JS, Schenk JO (1992) A multisubstrate mechanism of striatal dopamine uptake and its inhibition by cocaine. Biochem Pharmacol 43:2189-2199.

Missale C, Castelletti L, Govoni S, Spano PF, Trabucchi M, Hanbauer I (1985) Dopamine uptake is differentially regulated in rat striatum and nucleus accumbens. J Neurochem 45:51-56.

Moghaddam B, Bunney BS (1989) Differential effect of cocaine on extracellular dopamine levels in rat medial prefrontal cortex and nucleus accumbens: comparison to amphetamine. Synapse 4:156-161.

Paxinos G, Watson C (1986) The rat brain in stereotaxic coordinates. New York: Academic

Pontieri FE, Tanda G, Di Chiara G (1995) Intravenous cocaine, morphine, and amphetamine preferentially increase extracellular dopamine in the "shell" as compared with the "core" of the rat nucleus accumbens. Proc Natl Acad Sci USA 92:12304-12308.

Povlock SL, Schenk JO (1997) A multisubstrate kinetic mechanism of dopamine transport in the nucleus accumbens and its inhibition by cocaine. J Neurochem 69:1093-1105.

Povlock SL, Meiergerd SM, Schenk JO (1996) Kinetic mechanisms of the dopamine transporter: a comparison with other biogenic transporters. In: CNS neurotransmitters and neuromodulaters dopamine (Stone TW, ed), pp 21-39. Boca Raton, FL: CRC.
Press WH, Flanery BP, Teukolsky SA, Fetterline WT (1989) Numerical recipes in pascal. Cambridge, UK: Cambridge UP.

Rice ME, Nicholson C (1995) Diffusion and ion shifts in the brain extracellular microenvironment and their relevance for voltammetric measurements. In: Neuromethods, voltammetric methods in brain systems (Boulton A, Baker G, Adams RN, eds), pp 27-81. Totowa, NJ: Humana.

Sokal RR, Rohlf FJ (1995) Biometry. New York: Freeman.

Stamford JA, Kruk ZL, Millar J (1986) In vivo voltammetric characterization of low affinity striatal dopamine uptake: drug inhibition profile and relation to dopaminergic innervation density. Brain Res 373:85-91.

Sulzer D, Chen TK, Lau YY, Kristensen H, Rayport S, Ewing A (1995) Amphetamine redistributes dopamine from synaptic vesicles to the cytosol and promotes reverse transport. J Neurosci 15:4102-4108.

Tuomisto J (1977) Nomifensine and its derivatives as possible tools for studying amine uptake. Eur J Pharmacol 42:101-106.

Wang LC, Berfield JL, Kuhar MJ, Carroll FI, Reith ME (2000) RTI-76, an isothiocyanate derivative of a phenyltropane cocaine analog, as a tool for irreversibly inactivating dopamine transporter function in vitro. Naunyn Schmiedebergs Arch Pharmacol 362:238-247.

Wheeler DD, Edwards AM, Chapman BM, Ondo JG (1994) Effects of cocaine on sodium dependent dopamine uptake in rat striatal synaptosomes. Neurochem Res 19:49-56.

Wiedemann DJ, Kawagoe KT, Kennedy RT, Ciolkowski EL, Wightman RM (1991) Strategies for low detection limit measurements with cyclic voltammetry. Anal Chem 63:2965-2970.

Wightman RM, Zimmerman JB (1990) Control of dopamine extracellular concentration in rat striatum by impulse flow and uptake. Brain Res Brain Res Rev 15:135-144.

Wightman RM, Amatore C, Engstrom RC, Hale PD, Kristensen EW, Kuhr WG, May LJ (1988) Real-time characterization of dopamine overflow and uptake in the rat striatum. Neuroscience 25:513-523.

Wise RA (1996) Addictive drugs and brain stimulation reward. Annu Rev Neurosci 19:319-340.

Zahniser NR, Larson GA, Gerhardt GA (1999) In vivo dopamine clearance rate in rat striatum: regulation by extracellular dopamine concentration and dopamine transporter inhibitors. J Pharmacol Exp Ther 289:266-277. 